\section{International facilities said to boost national economy}

London. A report published by the UK Office of Science and Technology (OST) challenges the traditional view of the Treasury that hosting an international scientific facility has little long-term impact on the economy of the host nation.

The report, prepared by the consulting group Segal Quince Wicksteed of Cambridge, says that international facilities can boost the long-term economic fortunes of companies that supply them with equipment and services, act as a magnet for other hightechnology companies and generally raise the public profile of science. Although it is difficult to calculate the extent to which the funds represent a net gain to the economy, according to the report, the income and value added tax paid to the government by foreign scientists and other employees represents a clear economic gain.

The Treasury has accepted the idea that international facilities are a cost-effective way to support large-scale research, but it has been reluctant to provide financial incentives to attract such facilities to Britain, following the example of France and Switzerland, because of doubts that they contribute to the country's economic wealth. This conclusion is challenged by an analysis of spending on equipment and salaries at four international scientific centres: the Joint European Torus (JET) at Culham, England; the European Laboratory for Particle Physics (CERN) at Geneva, Switzerland; and the European Synchrotron Radiation Facility (ESRF) and the Institute Max von LauePaul Langevin (ILL), both in Grenoble, France.

Overall, the analysis found that between 40 and 70 per cent of the money to operate

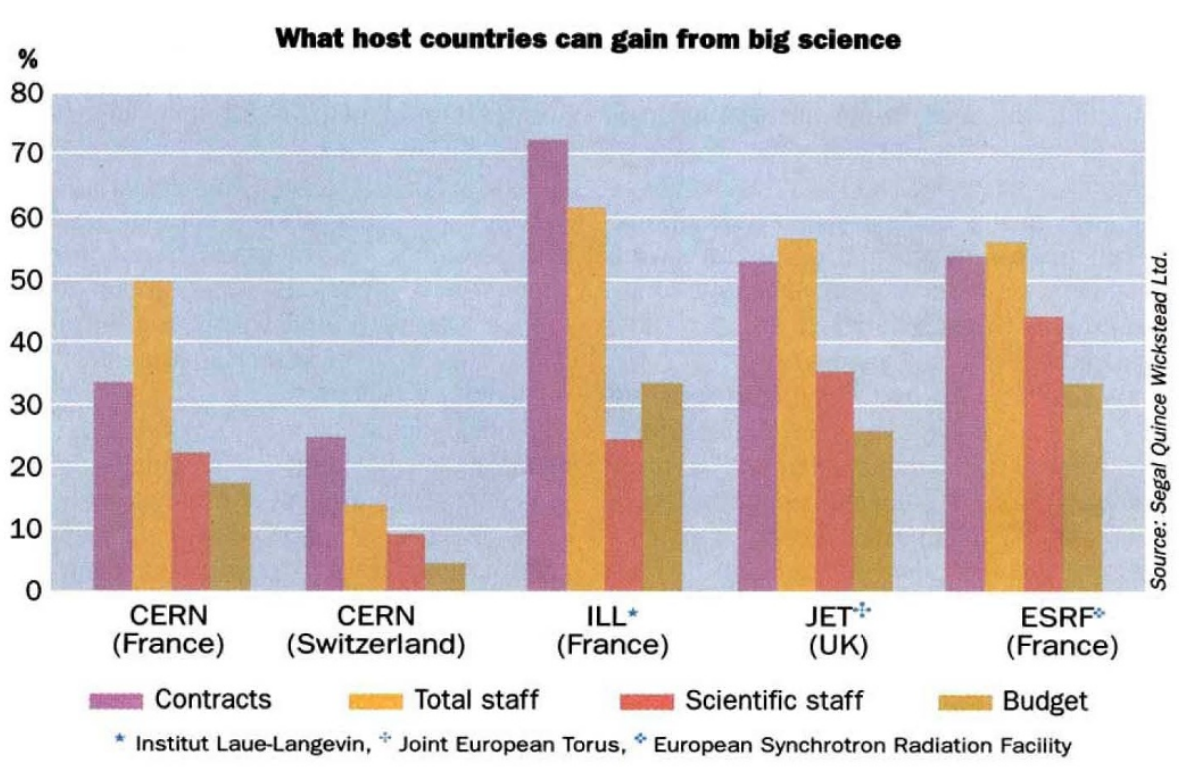

the facilities was spent in the host nation. While admitting that some of this funding could have displaced other funding sources - for example, technicians in short supply would likely have found alternative work the authors of the report, Robin Brighton and Virginia Aschas, say that they also found clear evidence of economic gain.

For example, in many cases local companies providing scientific equipment and other services were able to benefit from reduced delivery costs, personal contacts and a more detailed knowledge of a facility's needs. Those factors give them a competitive advantage in bidding on contracts. For scientists, the main economic advantage of having a facility in their home country is the reduced cost of travel and accommodation.

Brighton says that it is impossible to quantify the likely gains from an international facility, because a number of important factors (such as displacement costs) depend heavily on prevailing economic conditions. He says, however, that the study "produced enough evidence to suggest that the potential economic benefits [from an international facility] should be studied very carefully".

OST officials hope that demonstrating these likely gains will make it easier to obtain Treasury backing for any future bids to locate scientific facilities in Britain. At the top of the list is a European Neutron Source, a successor to the Nuclear Structure Facility at Daresbury that was closed down last month, which many physicists would like to see built at the Science and Engineering Research Council's Rutherford Appleton Laboratory.

David Dickson

\section{Swiss look for ways to reap benefits of next Framework}

Basel. Swiss researchers, who lost access to millions of dollars from the European Communities (EC) when voters decided in December to delay the process of joining the $\mathrm{EC}$, are waiting for the reaction to their government's attempt to participate at some level in the EC's fourth Framework Programme, which begins next year.

The referendum blocked Switzerland's entrance into the European Economic Area (EEA), the first step towards full EC membership. Switzerland already participates in some 200 individual EC projects, paying researchers the costs normally paid to full EC members, which average SFr30 million (US\$20 million) a year.

The change in status would have allowed Switzerland to participate fully in broader Framework programmes, although it would not yet have been eligible for direct financial support. Swiss researchers would also have been allowed to join programme committees and to serve as project leaders on individual projects.

The vote deprived Max Hess, an immunopathology professor at the University of Berne, of a promised position on the Biomed programme advisory commission. A third of the 140 projects in this programme have Swiss participation, he says. "The worst thing is that we get no information about what is going on", he says.

Fred Paccaud, a professor of social medicine from the University of Lausanne, held a special exemption to serve as a project leader in the MR4 programme, a predecessor of the Biomed programme, but his proposal to continue working on Biomed was rejected in January. "I was told I am no longer entitled to apply", he says.

Tim Guldimann, head of economics and foreign policy in the Swiss science policy coordinating group, says that all sides suffer from the exclusion of Swiss researchers. With three per cent of its gross national product devoted to research and development, the country ranks with Japan as the heaviest investor of science in the world.

The Swiss government was prepared to pay SFr477 million to participate in the fourth Framework programme and had encouraged researchers and industry to submit proposals. These proposals are now being used as a negotiating tool to demonstrate Switzerland's strength in particular areas. The EC Council of Ministers needs to establish a general mechanism for negotiating with Switzerland now that it is the only country in Europe that has neither EC nor EEA status. Last week it agreed in principle that Switzerland could take part in projects where its participation would strengthen the research effort.

Oliver Klaffike 